\title{
Translocação e compartimentalização de Zn em função de doses aplicadas em feijoeiro e cafeeiro via radicular ${ }^{1}$
}

\author{
Translocation and compartmentation of $\mathrm{Zn}$ doses applied to roots of bean \\ and coffee seedlings
}

\author{
Hermínia Emilia Prieto Martinez ${ }^{2}$ André Vinicius Zabini ${ }^{3}$ \\ Ivan Alencar de Lima Franco ${ }^{3}$ Roberto Ferreira de Novais ${ }^{4}$
}

\section{RESUMO}

O objetivo do presente trabalho foi avaliar a mobilidade e a compartimentalização de $\mathrm{Zn}$ aplicado via radicular em feijoeiro e cafeeiro. Foram instalados dois experimentos em casa de vegetação, em solução nutritiva, em sistema de vasos geminados, sendo o sistema radicular igualmente dividido nos dois recipientes. Em um dos recipientes geminados, adicionou-se uma solução sem $\mathrm{Zn} e$, no outro, foram aplicadas doses crescentes do elemento (0,0; 0,$5 ; 1,0 ; 2,0 ; 3,0 ; 4,0 \mu m o l L^{-1}$ ) na forma de $\mathrm{ZnSO}_{4}$, as quais constituíram os tratamentos no delineamento em blocos ao acaso com quatro repetições. O Zn apresentou mobilidade no floema do feijoeiro, indicando ser retranslocado da parte aérea para o sistema radicular. Já no cafeeiro, o $\mathrm{Zn}$ demonstrou praticamente imobilidade no floema. As plantas de feijoeiro apresentaram resposta linear crescente, em função das doses de $\mathrm{Zn}$, para o teor $\mathrm{Zn}$ nas diferentes partes analisadas. Plantas de cafeeiro apresentaram mínima alteração no peso da matéria seca e teor de $\mathrm{Zn}$ na parte aérea. O caule apresentou-se como um local de concentração de $\mathrm{Zn}$, tanto em cafeeiro como em feijoeiro.

Palavras-chave: Coffea arabica, Phaseolus vulgaris, micronutriente, mobilidade.

\section{ABSTRACT}

Two experiments were conducted aiming at evaluating translocation and compartmentation of zinc applied on roots of bean and coffee seedlings in greenhouse grown in nutrient solution. The plants were grown in geminate containers system and nutrient solution containing 0,$0 ; 0,5$; $1.0 ; 2.0 ; 3.0 ; 4.0 \mu \mathrm{mol} \mathrm{L} \mathrm{L}^{-1}$ of zinc by $\mathrm{ZnSO}_{4}$, which ones constituted the treatments. The dry matter and total zinc concentration were determined in the stems, roots, upper leaves and lower leaves. Total zinc analysis showed translocation of zinc towards the roots in bean, indicating zinc mobility in phloem of these plants. However, in coffee seedlings zinc showed minimum mobility in phloem. The bean plants presented linear increasing in zinc concentration in the different analyzed parts because of treatments. Coffee seedlings showed minimum alteration in the dry matter and zinc concentration in the aerial part. The stem showed to be a concentration location of zinc in coffee and in bean seedlings as well.

Key words: Coffea arabica, Phaseolus vulgaris, micronutrient, mobility.

\section{INTRODUÇÃO}

A deficiência de Zn ocorre amplamente em solos brasileiros e de outras partes do mundo. Quando crescidas nesses solos, culturas como o cafeeiro e o feijoeiro podem tornar-se deficientes em $\mathrm{Zn}$, provocando redução no crescimento. Mesmo a deficiência de Zn ocorrendo em estádios iniciais de crescimento da planta, pode resultar em perda substancial na produção final. Pesquisas sobre

\footnotetext{
${ }^{1}$ Parte da dissertação apresentada pelo terceiro autor à Universidade Federal de Viçosa para obtenção do título de Doutor em Fitotecnia.

${ }^{2}$ Professor Adjunto do Departamento de Fitotecnia, Universidade Federal de Viçosa, 36571-000, Viçosa, MG, Brasil. E-mail: hermínia@mail.ufv.br

${ }^{3}$ Pós-graduando do Departamento de Fitotecnia, Universidade Federal de Viçosa, 36571-000, Viçosa, MG, Brasil. E-mail: zabini@hotmail.com

${ }^{4}$ Professor Titular do Departamento de Solos, Universidade Federal de Viçosa, 36571-000, Viçosa, MG, Brasil. E-mail: rfnovais@mail.ufv.br
} 
transporte e distribuição de Zn dentro da planta, as quais podem melhorar a eficiência da aplicação do nutriente, têm recebido pouca atenção (PEARSON \& RENGEL, 1994).

O Zn é elemento parcialmente móvel dentro da planta (PEASLEE et al., 1981). Entretanto, FÁVARO (1992), estudando a aplicação foliar de Zn em cafeeiro, observou baixíssima mobilidade ou mesmo imobilidade do Zn quando aplicado em folha madura. Já em experimentos com trigo, utilizando raízes subdivididas, LONERAGAN et al. (1987) e MARSH et al. (1985) observaram certa mobilidade de Zn. Nesse mesmo sentido, PEARSON \& RENGEL (1995a) observaram que plantas de trigo com 14 e 42 dias de idade tiveram cerca de $25 \%$ do total do ${ }^{65} \mathrm{Zn}$ transportado, distribuído para a raiz não-exposta ao Zn marcado, atribuindo esse fato à criação de uma demanda por Zn. Relataram ainda que o ${ }^{65} \mathrm{Zn}$ foi translocado das raízes para a parte aérea via transpiração, mas a retranslocação para as outras partes do sistema radicular que não receberam ${ }^{65} \mathrm{Zn}$ pode ter requerido movimentação dentro do floema. Observaram também que as plantas pré-crescidas em condição de deficiência alocaram menos Zn para raízes não-expostas ao ${ }^{65} \mathrm{Zn}$ e mais para o caule, em termos percentuais. Armazenamento temporário de Zn no caule é relatado por PEARSON \& RENGEL (1994) em trigo, como podendo ser um evento importante para alguns íons, que parecem ser relativamente imóveis dentro do floema, já que possibilitaria a remobilização via xilema. Os autores também observaram que nenhum $\mathrm{Zn}$ foi retirado do caule em plantas de trigo nos primeiros 14 dias do desenvolvimento do grão, sendo quantidades substanciais retiradas do caule após esse período, em direção ao amadurecimento do grão.

O presente estudo teve por objetivo avaliar a mobilidade do Zn, aplicado via radicular, no xilema e no floema, bem como a compartimentalização do elemento em cafeeiro e feijoeiro.

\section{MATERIAL E MÉTODOS}

Plantas de feijão (Phaseolus vulgaris L. cv. Ouro Negro) e de café (Coffea arábica L. cv. Catuaí Vermelho) foram cultivadas em sistema de hidroponia estática com arejamento constante e pH das soluções mantido em 5,0 \pm 0,5. Para o primeiro ensaio, plântulas de feijoeiro, obtidas por semeadura em germinador, foram selecionadas e transferidas para bandejas de 26L de capacidade, contendo solução nutritiva de CLARK (1975) aerada. Todas as soluções-estoque de macronutrientes foram submetidas à técnica de purificação para a remoção de $\mathrm{Zn}$, com o reagente pirrolidina ditiocarbamato de amônio (APDC), usando- se como solvente o clorofórmio (FONTES, 1986). Dentre os micronutrientes, somente o cloreto férrico foi purificado, utilizando-se a resina Dower $1 \mathrm{X}-8$ (FONTES, 1986).

As plântulas de feijoeiro, após 15 dias de condução nas soluções das bandejas, tiveram sua raiz principal podada a $1 \mathrm{~cm}$ do coleto, a fim de induzir a sua bifurcação, sendo então transferidas para vasos geminados com 3L de capacidade cada, e o sistema radicular dividido nos dois recipientes (Figura 1). Em cada vaso geminado, um dos recipientes foi sempre preenchido com solução sem $\mathrm{Zn}$, e o outro com soluções com doses crescentes do elemento: 0,0; 0,5; 1,0; 2,0; 3,0 e 4,0 $\mu \mathrm{mol} \mathrm{L}{ }^{-1}$ na forma de $\mathrm{ZnSO}_{4}$, as quais constituíram os tratamentos instalados no delineamento em blocos ao acaso com quatro repetições. O experimento foi conduzido em vasos geminados durante vinte dias, com as plantas atingindo de 11 a 12 trifólios.

O segundo ensaio, com plantas de café, foi conduzido da mesma forma que o primeiro, com solução nutritiva de mesma composição e pH. Após a germinação, as mudas de café foram transferidas para bandejas de $26 \mathrm{~L}$ de capacidade contendo solução de CLARK (1975) aerada e, após um mês de condução, tiveram sua raíz principal podada a $1 \mathrm{~cm}$ do coleto.

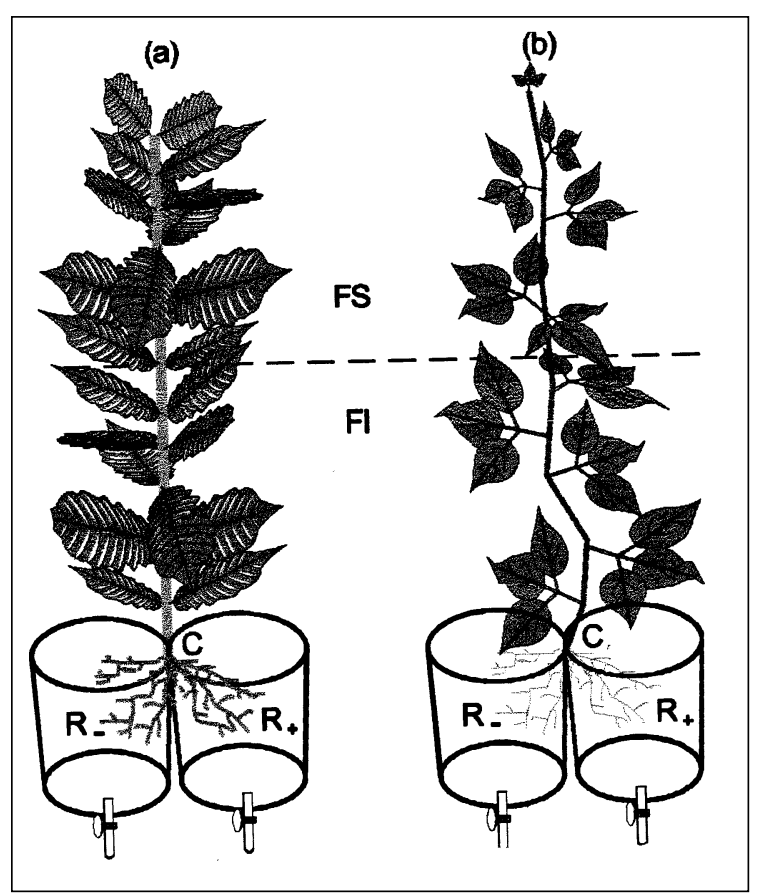

Figura 1: Representação esquemática dos vasos geminados e da divisão de cafeeiro(a) e de feijoeiros (b) por ocasião da colheita: FI, folha inferior; FS, folha superior; C, caule; R- raiz sem zinco; $\mathrm{R}+$ raiz com níveis de $\mathrm{Zn}$.

Ciência Rural, v.35, n.3, mai-jun, 2005. 
Durante o primeiro mês, a solução nutritiva utilizada continha Zn na concentração de $1,0 \mu \mathrm{mol} \mathrm{L} \mathrm{L}^{-1}$, sendo posteriormente substituída por solução sem Zn. Após três meses na solução das bandejas, as mudas de cafeeiro foram transferidas para os vasos geminados, onde permaneceram durante cinco meses.

Os ensaios com o cafeeiro e o feijoeiro foram avaliados da mesma forma. Foram coletadas folhas da porção inferior (até o $5^{\circ}$ par de folhas ou trifólio), porção superior (folhas restantes), além do caule e raízes (Figura 1). As raízes crescidas na ausência de Zn foram coletadas e analisadas separadamente das raízes que receberam as doses de $\mathrm{Zn}$. As diferentes partes foram lavadas em água desionizada, secas em estufa de circulação de circulação forçada a $70-75^{\circ} \mathrm{C}$ até peso constante, pesadas, moídas e mineralizadas por digestão nítrico-perclórica, sendo a concentração de Zn neste extrato obtida por espectrofotometria de absorção atômica (MALAVOLTA et al, 1997). Foram realizadas análises de variância e regressão, sendo os modelos ajustados aos níveis de significância de 0,1 , 1 e $5 \%$ de probabilidade.

\section{RESULTADOS E DISCUSSÃO}

A concentração de Zn, em todas as partes analisadas do feijoeiro, apresentou incrementos lineares com o aumento das doses do elemento em solução (Figura 2). As folhas da porção superior das plantas, na dose $0,0 \mu \mathrm{mol} \mathrm{L}{ }^{-1}$ de $\mathrm{Zn}$ apresentaram maior concentração do elemento que as folhas da porção inferior e, nas maiores doses de Zn em solução, as

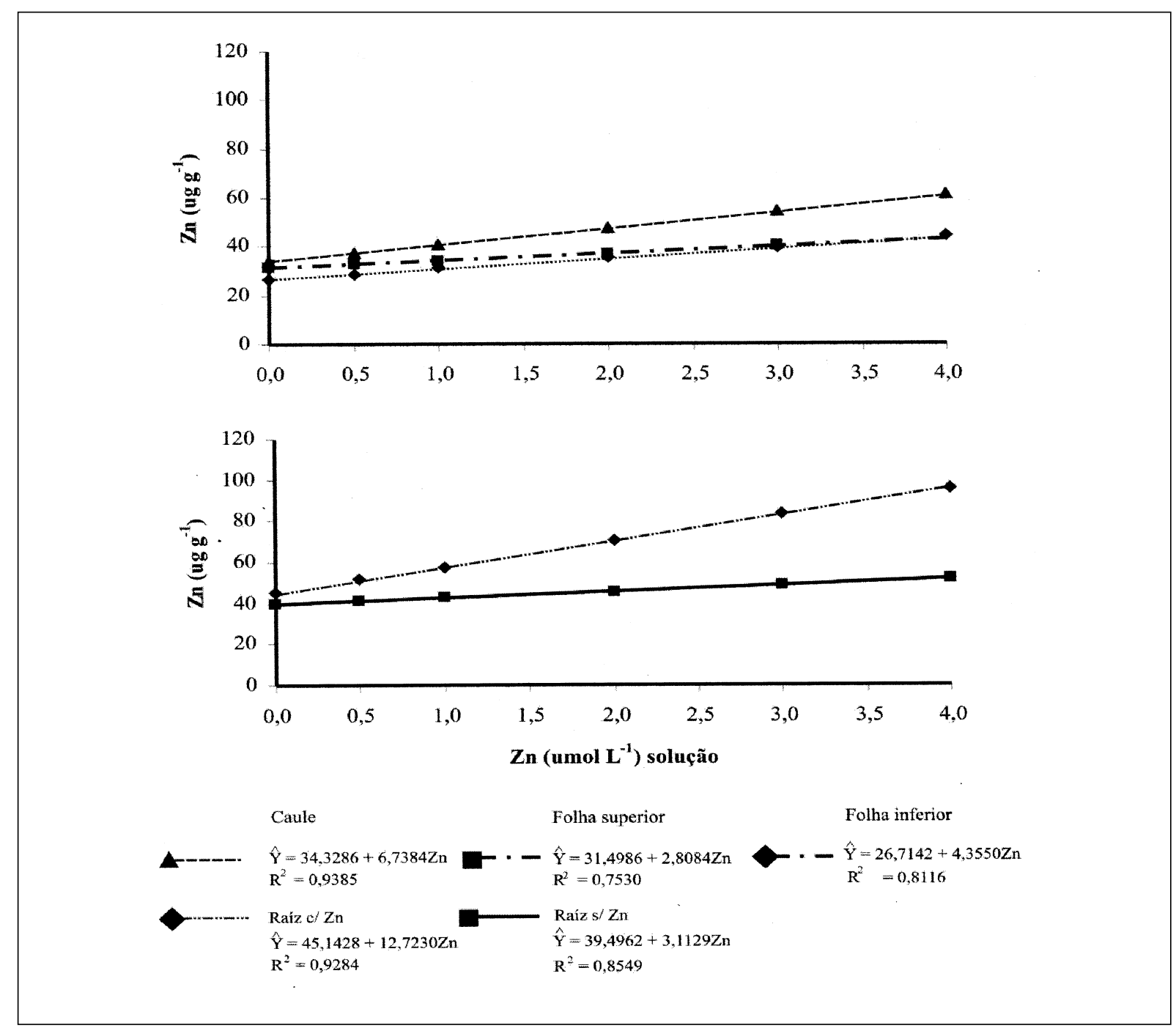

Figura 2 - Teor estimado de Zn em parte aérea e raízes de feijoeiro, em função de doses de Zn na solução nutritiva.

Ciência Rural, v.35, n.3, mai-jun, 2005. 
folhas da porção inferior passaram a apresentar maior teor de Zn que as folhas da porção superior, indicando que, em plantas crescidas em condição de deficiência de Zn, as folhas superiores ou em crescimento são drenos mais fortes, criando demanda maior por Zn que as folhas da porção inferior. Essas observações concordam com as de LONGNECKER \& ROBSON (1993), os quais relataram que tecidos em crescimento são drenos preferenciais de Zn em relação a tecidos maduros. Para as plantas conduzidas nas doses mais elevadas de $\mathrm{Zn}$, o efeito de dreno dos tecidos em crescimento não se apresentou tão forte. Essa maior concentração em tecidos jovens em condição de deficiência pode ser um indicativo da mobilidade do Zn em plantas de feijão, pois mostra que houve translocação preferencial de $\mathrm{Zn}$ dos tecidos maduros para os tecidos em crescimento.

Os teores foliares estimados de $\mathrm{Zn}$ com a dose $0,0 \mu \mathrm{mol} \mathrm{L}^{-1}$ de Zn na solução foram $31,50 \mu \mathrm{g} \mathrm{g}^{-1} \mathrm{e}$ 26,71 $\mu \mathrm{g} \mathrm{g}^{-1}$ (Figura 2) para as folhas da porção superior e inferior do feijoeiro, respectivamente. Os aspectos visuais apresentados, que foram redução do comprimento do caule, clorose e textura coriácea das folhas, indicam que o feijoeiro apresentava-se deficiente nessa dose. $\mathrm{O}$ aumento da concentração na parte aérea do feijoeiro, acima desses valores com as maiores doses de $\mathrm{Zn}$, indica que a parte do sistema radicular imerso nos compartimentos com doses crescentes do elemento foi capaz de sustentar o desenvolvimento da planta, pois a concentração das folhas nas doses mais elevadas superou aqueles valores em que as plantas apresentaram sintomas de deficiência.

Observando-se a planta como um todo, em todas as doses, o caule apresentou, em termos gerais, a segunda maior concentração de $\mathrm{Zn}$, sendo menor somente que a do sistema radicular que recebeu $\mathrm{Zn}$ (Figura 2). Esses resultados se assemelham aos relatos de PEARSON \& RENGEL (1994), os quais observaram que o caule de plantas de trigo representava o segundo maior compartimento de Zn. Nesse sentido, o caule tem sido descrito como uma área temporária para acúmulo de micronutrientes em pinus (McGRATH \& ROBSON, 1984), e trigo (PEARSON \& RENGEL, 1994; PEARSON \& RENGEL, 1995b).

Houve resposta linear crescente para os teores de $\mathrm{Zn}$ nas raízes, tanto na ausência quanto na presença das doses de Zn (Figura 2), indicando que parte do Zn fornecido à raiz crescida na presença do elemento foi translocada para a parte aérea e retranslocada para a raiz crescida em sua ausência. Relatos semelhantes de translocação de Zn do sistema radicular suprido com o elemento, para a outra parte do sistema radicular cultivado em ausência de Zn, caracterizando uma certa mobilidade, foram obtidas em trigo (LONERAGAN et al., 1987; PEARSON \& RENGEL, 1995a) e caupi (MARSH et al., 1985).

As doses de $\mathrm{Zn}$ promoveram resposta quadrática para a produção de matéria seca de folhas e das raízes do feijoeiro (Figura 3). Para matéria seca de caule e raízes cultivadas sem Zn não houve ajuste de equação, indicando que os níveis de $Z n$ não afetaram a matéria seca dessas partes do feijoeiro. A matéria seca de folhas e das raízes que receberam as doses de Zn apresentaram produções máximas de 9,97 e 1,29 g nas concentrações de $2,4 \mu \mathrm{mol} \mathrm{L}-1$ e $2,2 \mu \mathrm{mol} \mathrm{L}^{-1}$ de $\mathrm{Zn}$ na solução nutritiva, respectivamente. A partir desses pontos, o aumento da concentração de Zn na solução nutritiva restringiu a produção de matéria seca da planta, indicando provavelmente um efeito tóxico.

No experimento com cafeeiro, os resultados de teores de Zn de todas as partes da planta analisadas (Figura 4) foram diferentes dos observados no experimento com feijoeiro (Figura 2). Somente à concentração de Zn do sistema radicular que recebeu as doses de $\mathrm{Zn}$ foi possível ajustar-se equação de regressão, sendo que as concentrações das demais partes das planta não responderam aos níveis de Zn aplicados. Na figura 4, observa-se ainda que o teor médio estimado de 23,55 $\mu \mathrm{g} \mathrm{g}^{-1}$, para o sistema radicular crescido na ausência de $Z n$ em solução, não foi alterado pelas doses de $\mathrm{Zn}$ fornecidas à outra parte do sistema radicular, indicando que o $\mathrm{Zn}$ não se retranslocou da parte aérea para o sistema radicular. $\mathrm{O}$ $\mathrm{Zn}$ pode ter ascendido de acordo com o fluxo transpiratório até a parte aérea via xilema, como relatado por PEARSON \& RENGEL (1995a), mas não ocorreu sua transferência para o floema, como observado para o feijoeiro, demonstrando que, em cafeeiro, o Zn apresenta retranslocação limitada ou até mesmo nula. WEBB \& LONERAGAN (1990) relataram que o $\mathrm{Zn}$ se moveu em plantas de trigo das folhas para os grãos em desenvolvimento, mas não das folhas para as raízes, quando aplicado via foliar. No entanto, MALTA et al. (2003) verificaram incrementos significativos no conteúdo de Zn do sistema radicular, caule e folhas da base de mudas de cafeeiro cv. Acaiá do Cerrado MG 1474, quando estas receberam aplicações foliares de $\mathrm{Zn}$, independente da posição de aplicação (basal ou apical), sugerindo que houve translocação de Zn para a porção inferior da planta. Uma possível explicação para esta contradição de resultados encontra-se na quantidade de $\mathrm{Zn}$ fornecida à planta, ou seja, enquanto MALTA et al. (2003) aplicaram $15 \mathrm{ml}$ de solução de $\mathrm{ZnSO}_{4}$ a $0,6 \%$ por planta, ou equivalente a 20,38mg de $\mathrm{Zn}$ por planta, 
neste trabalho a maior dose de Zn em solução (4,0 $\mu$ mol $\mathrm{L}^{-1}$ ) corresponde a apenas $0,78 \mathrm{mg}$ de $\mathrm{Zn}$ por planta. Neste sentido, uma concentração elevada de Zn nas folhas pode ter favorecido o carregamento no floema e conseqüentemente a translocação para regiões basais.

A ausência de resposta da concentração de $\mathrm{Zn}$ em diferentes partes da planta, aos níveis crescentes de $\mathrm{Zn}$, indica que, apesar do aumento da concentração da solução nutritiva, a movimentação de Zn para a parte aérea pode ter-se mantido constante, independentemente da concentração da solução nutritiva. O teor médio de $\mathrm{Zn}$ das folhas superiores e inferiores foi maior que o valor crítico de deficiência de Zn de $10 \mu g^{-1}$ para café (MALAVOLTA et al., 1997), indicando que, mesmo na dose $0,0 \mu \mathrm{mol} \mathrm{L}^{-1}$ de $\mathrm{Zn}$, as reservas de $\mathrm{Zn}$ da planta foram capazes de sustentar a concentração na parte aérea acima do valor crítico de deficiência nas folhas. O valor médio de matéria seca de folhas (Figura 5) reforça essa idéia, pois em qualquer dos níveis utilizados, a matéria seca de folhas mantevese constante.

O teor médio de Zn na folha superior do cafeeiro foi maior que o da folha inferior (Figura 4). Esse fato pode indicar o efeito de dreno que a região superior em crescimento, metabolicamente mais ativa, exerce (LONGNECKER \& ROBSON 1993). Como observado para o feijoeiro, mas em maior proporção, o

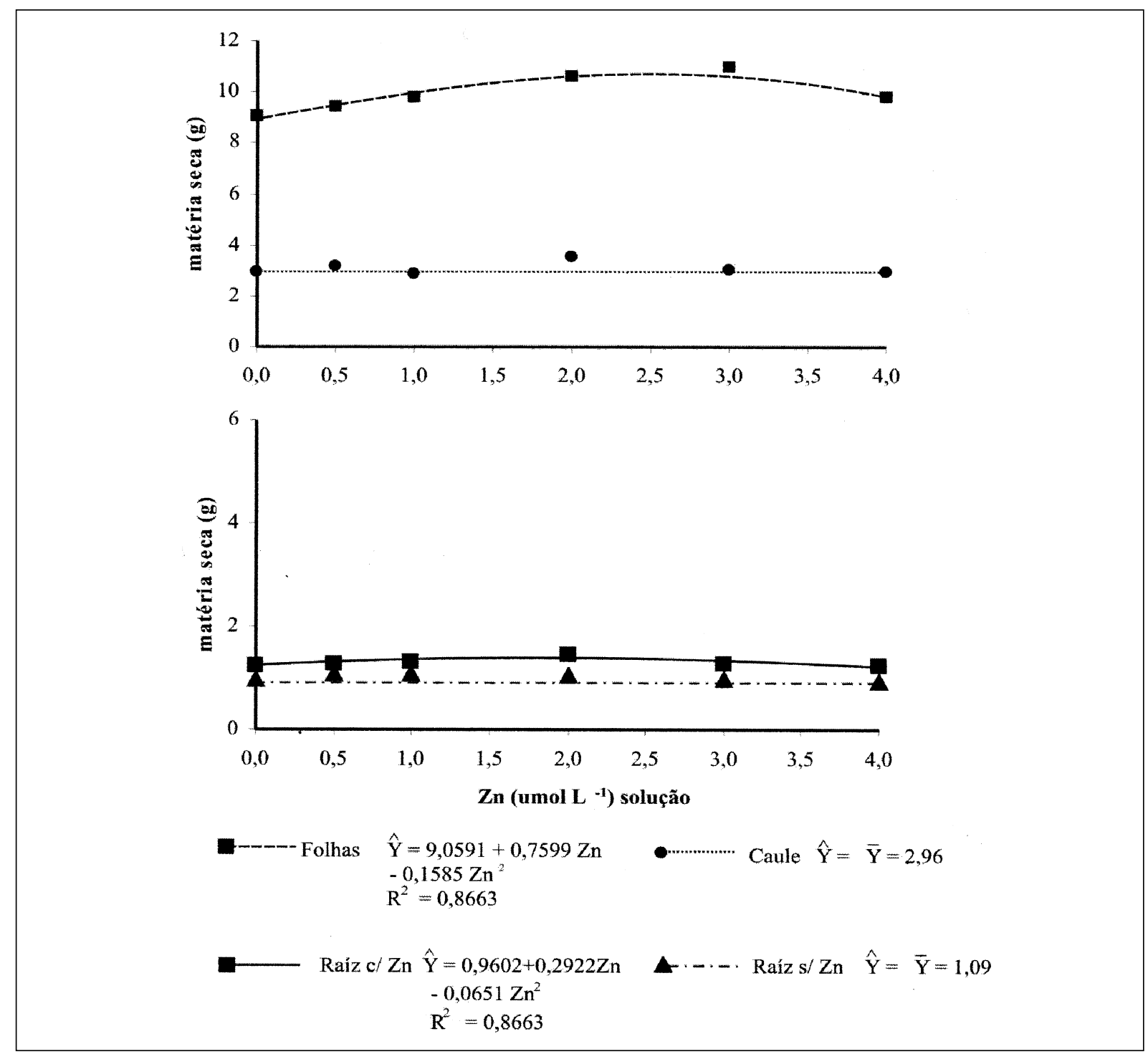

Figura 3 - Matéria seca de parte aérea e de raízes de feijoeiro, em função de doses de Zn em solução nutritiva

Ciência Rural, v.35, n.3, mai-jun, 2005. 

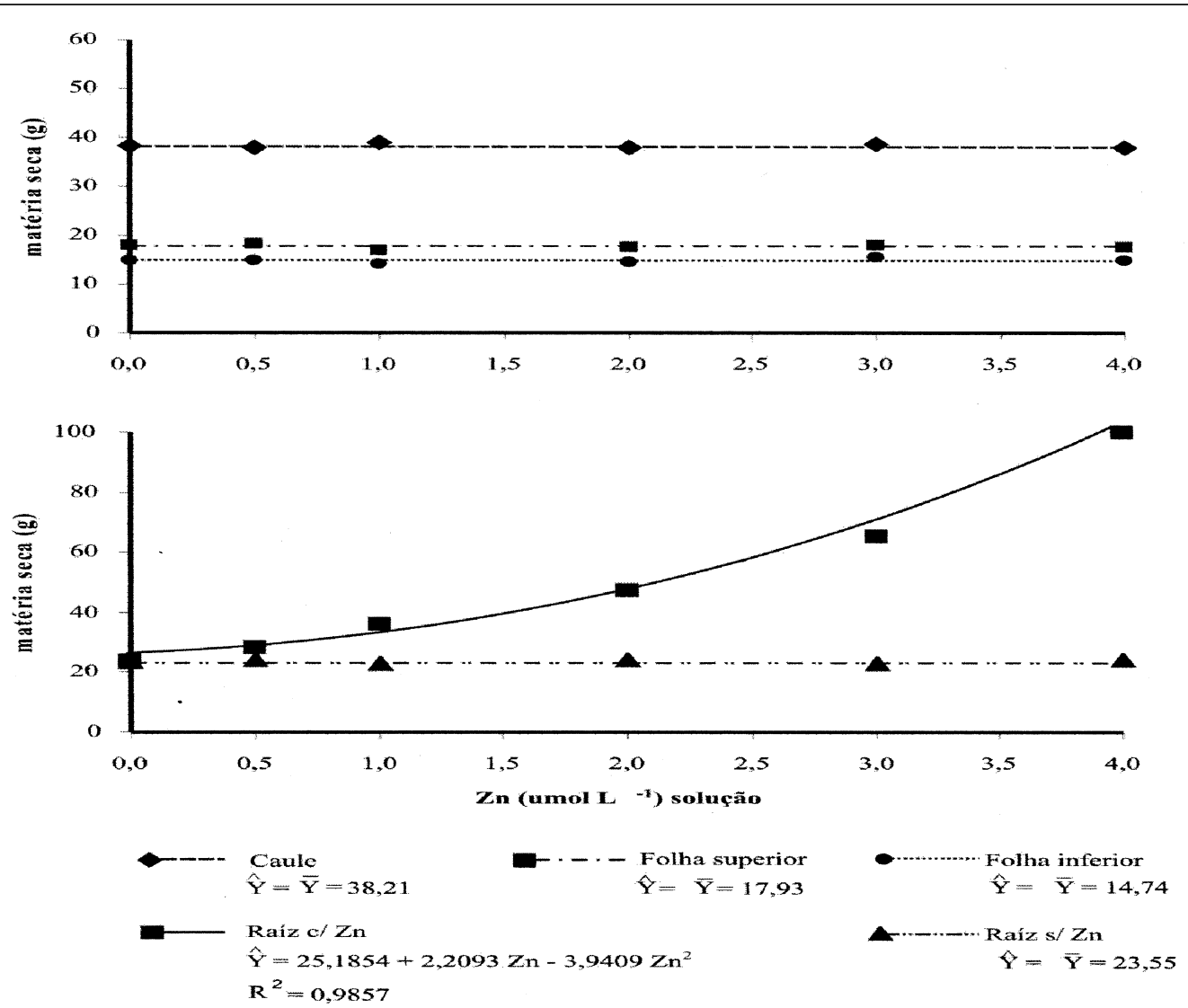

Figura 4 - Teor de Zn na parte aérea e raízes de cafeeiro em função de doses de Zn na solução nutritiva.
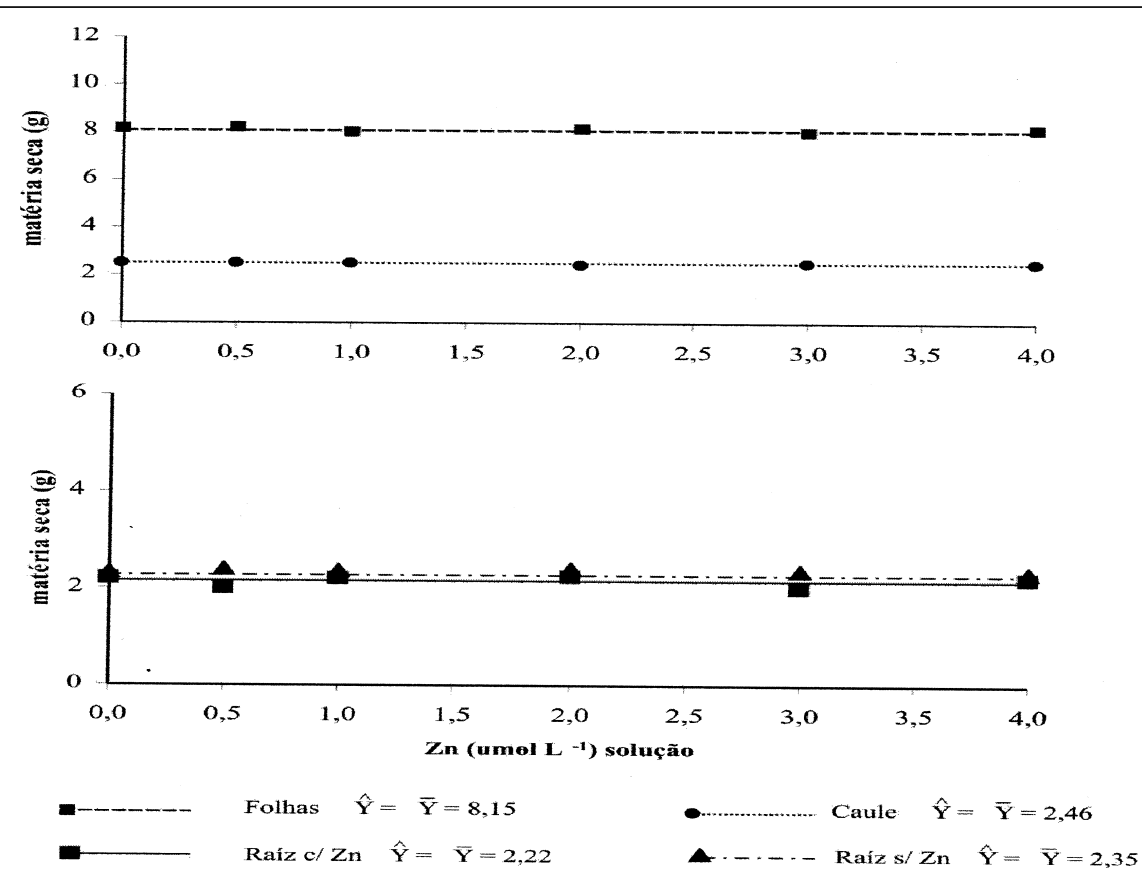

Figura 5 - Matéria seca de parte aérea e de raízes de cafeeiro, em função de doses de Zn em solução nutritiva.

Ciência Rural, v.35, n.3, mai-jun, 2005. 
teor médio de Zn no caule do cafeeiro foi bem superior aos teores observados para as suas folhas (Figura 4). Semelhantemente, PEARSON \& RENGEL (1994) observaram, em plantas de trigo, armazenamento temporário de Zn no caule, concluindo que esse fato pode ser um evento importante para alguns íons, os quais parecem ser relativamente imóveis no floema, podendo a sua remobilização, quando necessária, ser feita via xilema. No caso do cafeeiro, no qual o $\mathrm{Zn}$ aparentou ser pouco móvel no floema, essa concentração de $\mathrm{Zn}$ no caule pode participar no suprimento de $\mathrm{Zn}$ em períodos de deficiência do elemento (Figura 4).

A matéria seca (Figura 5) de todas as partes do cafeeiro (caule, folha e raíz) manteve-se constante, independentemente do aumento das doses de Zn, não havendo ajuste de equação para essa característica, e os níveis de $\mathrm{Zn}$ aplicados não afetaram significativamente o crescimento da planta, possivelmente devido à reserva de $\mathrm{Zn}$ contida na semente do café. A ausência de resposta foi constatada também para produção de matéria seca por plantas de trigo crescidas em condição de deficiência e suficiência de Zn (PEARSON \& RENGEL, 1994).

A quantidade média de matéria seca da raiz que recebeu os níveis de $\mathrm{Zn}$ foi ligeiramente menor que a matéria seca média da raiz que cresceu na solução sem Zn (Figuras 4 e 5). Essa pequena diferença pode ser reflexo de efeito tóxico das doses de $\mathrm{Zn}$ aplicadas.

\section{CONCLUSÕES}

O caule apresenta-se como local de armazenamento de $\mathrm{Zn}$, tanto em cafeeiro quanto em feijoeiro, mesmo que temporário, e não somente local do transporte deste nutriente. O Zn apresenta mobilidade no floema do feijoeiro e mínima mobilidade no floema do cafeeiro. A produção de matéria seca do feijoeiro foi influenciada pelas doses de $\mathrm{Zn}$.

\section{REFERÊNCIAS BIBLIOGRÁFICA}

CLARK, R.B. Characterization of phosphatase of intact morize roots. Journal of Agriculture and Food Chemistry, v.23, p.458-460, 1975.

ÁVARO, J.R.A. Crescimento e produção de Coffea arabica L. em resposta à nutrição foliar de zinco na presença de cloreto de potássio. 1992. 91f. Dissertação (Mestrado em solos e nutrição de plantas) - Curso de Pós-graduação em Fisiologia Vegetal, Universidade Federal de Viçosa.

FONTES, R.L.F. Purificação de soluções nutritivas para indução de deficiência de Zn e Cu em plantas. 1986. 72f. Dissertação (Mestrado em fisiologia vegetal) - Curso de Pós-graduação em Solos e Nutrição de Plantas, Universidade Federal de Viçosa.

LONERAGAN, J.F. et al. Translocation and function of zinc in roots. Journal of Plant Nutrition, v.10, n.9-16, p.12471254, 1987.

LONGNECKER, N.E.; ROBSON, A.D. Distribution and transport of $\mathrm{Zn}$ in Plants. In: ROBSON, A.D. (Ed). Zinc in soil and plants. Boston: Kluwer Academic, 1993. p.79-91.

MALTA, M.R. et al. Absorção e translocação de zinco aplicado via foliar em mudas de cafeeiro. Revista Ceres, v.50, n.288, p.251-259, 2003.

MALAVOLTA, E. et al. Avaliação do estado nutricional das plantas: princípios e aplicações. 2.ed. Piracicaba : Potafos, 1997. 319p.

MARSH, D.B. et al. The use of a split-root technique to study Zn moviment and activity in a nodulating cowpea root system. Hort Science, v.20, n.3, p.425-427, 1985.

McGRATH J.F.; ROBSON A.D. The distribution of zinc and the diagnosis of zinc deficience to seedlings of Pinus radiata D. Don. Australian Forestry Reserch, v.14, p.175-186, 1984.

PEARSON, J.N.; RENGEL, Z. Distribution and remobilization of $\mathrm{Zn}$ and Mn during grain development in wheat. Journal of Experimental Botany, v.45, n.281, p.1829-1835, 1994.

PEARSON, J.N.; RENGEL, Z. Uptake and distribution of ${ }^{65} \mathrm{Zn}$ and ${ }^{54} \mathrm{Mn}$ in wheat grown at sufficient and deficient level of $\mathrm{Zn}$ and $\mathrm{Mn}$. I. During vegetative growth. Journal of Experimental Botany, v.46, n.288, p.833-839, 1995a.

PEARSON, J.N.; RENGEL, Z. Uptake and distribution of ${ }^{65} \mathrm{Zn}$ and ${ }^{54} \mathrm{Mn}$ in wheat grown at sufficient and deficient levels of $\mathrm{Zn}$ and $\mathrm{Mn}$ II. During grain development. Journal of Experimental Botany, v.46, n.288, p.841845, $1995 b$.

PEASLEE, D.E. et al. Acumulation and tranlocation of zinc by two corn cultivars. Agronomy Journal, v.73, n.4, p.72932, 1981.

WEBB, W.J.; LONERAGAN, J.F. Zinc translocation to wheat roots and its implications for a phosphorus/zinc interaction in wheat plants. Journal of Plant Nutrition, v.13, n.12, p.1499-1515, 1990. 